\title{
How to Use Research Activity Tools in Bachelor Students Research Competence Formation
}

\author{
Gulaiym Zikirova1, Tolonbai Saadalov², Kandalatkhan Turdubaeva ${ }^{3}$, Zhypargul Abdullaeva ${ }^{*}$ (i) \\ ${ }^{1}$ Department of Pedagogics, Osh Technological University, Osh, Kyrgyzstan \\ ${ }^{2}$ Department of Physical and Mathematical Sciences, Osh Technological University, Osh, Kyrgyzstan \\ ${ }^{3}$ Department of Pedagogics, Osh Humanitarian Pedagogical Institute, Osh, Kyrgyzstan \\ ${ }^{4}$ Science and Research Department, Osh State University, Osh, Kyrgyzstan \\ Email: *jypar.science@oshsu.kg
}

How to cite this paper: Zikirova, G., Saadalov, T., Turdubaeva, K., \& Abdullaeva, Z. (2021). How to Use Research Activity Tools in Bachelor Students Research Competence Formation. Creative Education, 12, 19952001.

https://doi.org/10.4236/ce.2021.129152

Received: July 31, 2021

Accepted: September 4, 2021

Published: September 7, 2021

Copyright (C) 2021 by author(s) and Scientific Research Publishing Inc. This work is licensed under the Creative Commons Attribution International License (CC BY 4.0).

http://creativecommons.org/licenses/by/4.0/

\begin{abstract}
This article analyzing the application of research activities as a tool in bachelor's research competence formation. Research background is a determination of bachelors' research competence resulting in objective education systematic phenomena development. The research results in this work are objective knowledge reflected in the system of concepts in mathematical knowledge. To interpret the research competence definition, we consider bachelor students' research skills competence formation during mathematics courses by performing various types of research activities. Based on the analysis and generalization, a connection between research competencies formations was revealed through the bachelor students' research activities. In the higher education process, the scientific activity of bachelors planned and research competence is formed by effective problem teaching methods.
\end{abstract}

\section{Keywords}

Bachelors, Research Activity, Research Competence, Efficiency, Problematic, Tools

\section{Introduction}

Solving educational problems requires research competence, the goal of developing students' research skills determined by individual socialization requirements and implementation of practice-oriented education (Pankratova, 2011: p. 85). Research competence, according to most scientists, is one of the key competencies and is formed based on innate human qualities, research behavior, as 
well as a whole set of elements of various educational competencies. Research activity in the broadest meaning is an activity that implements the cognitive and intellectual needs of an individual and produces new knowledge (Ostylovskaya \& Shershneva, 2016: p. 85). One of the most important goals of all modern higher education programs is the formation of research competence in the field of future professional activities. With the development of society, the main directions of education have changed, and society was able to choose the best well-educated specialists, competent in their activities, who are accustomed to constantly improving their knowledge.

Depending on the situation, the attitude of modern teachers changes not only to provide students with ready-made knowledge but also to raise them to the level of a leader, who not only teaches students but also inspires their research competence (Akmatkulov, 1999). Specialists obtaining research competence can analyze factual information actively and productively, to create and to select new efficient algorithms, resources, technologies, and not just to use ready-made algorithms and facts (Galustyan et al., 2020: p. 206).

When analyzing the concept of research competence, the general concept of research is considered and the role of the bachelor in the formation of research competence is determined.

There is no doubt that a person is born with the need to study the environment because research helps him not only to understand the reality around him but also to find the right direction. In addition, in the process of research, a person develops self-knowledge, the ability to analyze, generalize and worldview is formed.

\section{Research Methods and Materials}

Research structure and content of mathematical competence in future technical specialists include axiological components mainly knowledge about mathematical facts. Research methods in this work are based on a type of students' activity consisting of studying problems and situations through a system of accumulated knowledge, searching for new ideas or ways, means and opportunities for their practical use. The following characteristics of the analysis were used in this article: scientific validity, methodology, originality, results and effectiveness (Bekboev, 2003).

In this article, we used analysis of previously published works on the research competence formation in bachelors, and various definitions about research competence arise in the educational process. Determination of students' skills such as analysis, synthesis, comparison, generalization, definition and considering elements of research competencies by research activities.

\section{Results and Discussions}

\subsection{Research Competence}

According to A.A. Akmatkulova definition given to the term research, research 
is "the process of scientific research of origin laws, development and transformation of an object, the phenomenon is existing materially or ideally in the social interests. Each real research is a combination of previous experience, existing knowledge and the use of tools, methods and approaches related to the object of research" (Bekboev, 2003). Thus, research requires the acquisition of a recognition tool.

We can conclude that research is a phenomenon of human culture, the essence of which lies in the knowledge of the world around us. The result of the research is objective knowledge, reflected in the system of concepts in a certain area. To interpret the definition of research competence, we will consider the concept of competence. An individual usually understands competence as the acquisition of relevant competencies.

Competence is a complex, multi-component concept. It characterizes a specific area of objects and processes, are implemented at different levels, that is, with different methods of thinking (analytical, critical, communicative), as well as practical skills, rational motivation. Research competence includes basic knowledge, skills, and abilities (Letina, 2020: p. 2) as shown in Figure 1.

\subsection{Skills Developed by Research Competence}

Philosophical, psychological and pedagogical literature analysis showed that skills that can be developed by research competence are the ability to practice, as a good example of systematic implementation practice and research that is based on a scientific framework (Schultes et al., 2021: p. 20), ability based on knowledge, experience and values acquired in the learning process, academic achievements and related learning outcomes reflecting their learning motivation as well as active engagement in academic research (Guo et al., 2021: p. 1), the whole structure of personality, general (universal) abilities and skills, readiness of a person to work. The research competence of a bachelor is the ability and willingness to independently carry out various types of research work following the identified problem and goal.

The fundamentalization of education can be achieved in different ways: 1)

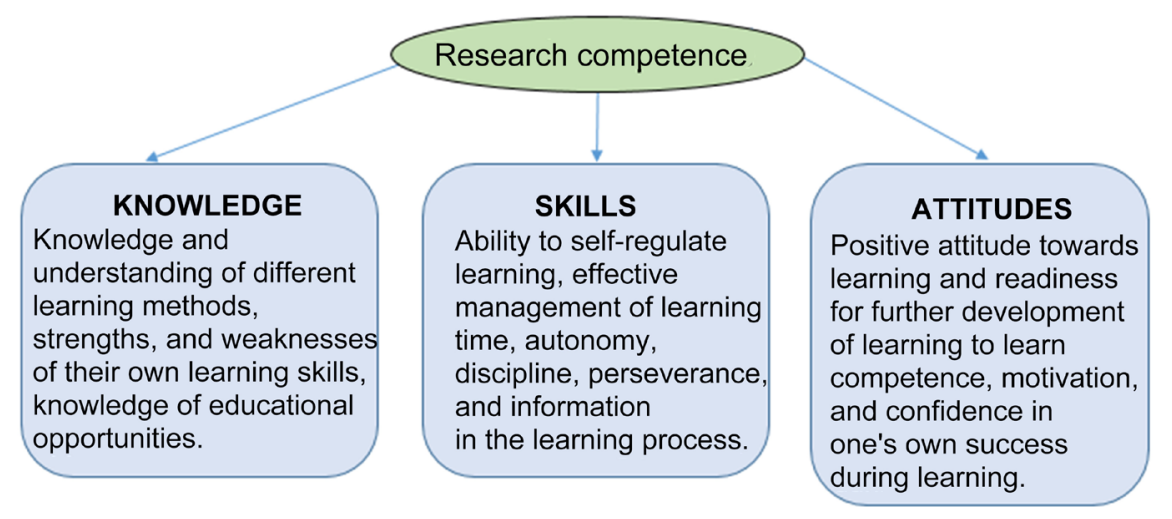

Figure 1. Knowledge, skills and attitudes are necessary components of research competence (adapted from Letina, 2020). 
changing the relationship between pragmatic and general cultural parts of education at all levels with priority given to problems of general culture development in a person, the formation of systemic thinking; 2) changes in the content and methodology of educational process, in which the emphasis is made on the fundamental disciplines study, created new training courses focused on formation of holistic ideas about the scientific picture of the world; 3) priority of information components promising system of fundamental education (Borovikova, 2014: p. 18).

In addition, we note that research activities are aimed at developing students' analytical skills using logical means of cognition (analysis, synthesis, comparison, generalization, analogy, definition and separation of concepts, etc., considering elements of research competencies (Shapoval, 2019: p. 79). According to the author, competence is "a set of interrelated qualities (knowledge, skills, abilities, methods of activity) of a person, necessary for a certain group of objects and processes and so that they can perform high-quality production activities" (Zikirova, 2019).

\subsection{Concepts "Competence" and "Research"}

The analysis and integration of concepts "competence" and "research" made it possible to determine the level of knowledge and skills in bachelor's research competence, as well as the experience of their practical application. Students' research skills and activities involve preparedness for performing creative actions when solving various research tasks on the level of research planning, collection of information, it is processing, fixing the initial and final research results, work, and use obtained results in practice (Lekomtseva, 2009: p. 92). Bachelors need to be able to present results of their research activities in an accessible way, both orally and in writing works. To do this, it is necessary to master general cultural competence, the ability to communicate orally and in writing in foreign languages to address issues of interpersonal and intercultural interaction.

In mastering this competence, bachelors should: be able to communicate orally and in writing during their studies; the ability to analyze and compare texts of different genres (annotations, abstracts, abstracts, annotations, etc.); the ability to determine the characteristics of texts in a given genre; the ability to comply with the requirements of regulatory oversight of research; should be able to translate the necessary information obtained from foreign sources for research.

It is now well known that teamwork is a research process. When working with a team, it is also important to adequately respond to criticism from peers. Hence, the bachelor must be able to work in a team, tolerate social, cultural and personal differences. Research competence of the bachelors of social work is consisting of the following components: motivational-target, processual-active, creative, communicative, reflexive and cognitive (Ananin, 2015: p. 146). To master this, bachelors require research skills consisting of the ability to coordinate teaching and research activities in the community including organization, interaction, division of responsibilities, decision making and implementation; have the ability to 
accept criticism and criticize oneself such as test scientific knowledge, have a culture of scientific discussion (Zikirova, 2019). In the process of higher education, bachelor's research activities planned and formation of bachelor's research competencies using problem-based teaching methods are efficient (Zikirova, 2020: p. 275).

\subsection{Students Self Organization and Independent Work}

Students' ability to self-organize and study independently plays an important role in research activities formation. Having mastered these, bachelors must have the following skills: the ability to search, evaluate, select and structure providing information; the ability to draw data directly from experience; the ability to formulate the goals and study objectives; the ability to plan research activities; be able to design, organize and monitor research. Based on the teaching theory principles, the following functions of self-organization were performed such as setting goals; diagnostics and evaluation; information; consider regulation separately.

Following the government provisions in standard higher professional education in the Kyrgyz Republic, the main didactic conditions for teaching mathematics include contextual learning, mathematics interdisciplinary integration course both with the natural and mathematical cycle disciplines (Zikirova et al., 2021).

By performing various types of research, bachelors independently defend results of their research. Therefore, bachelors must have general professional competencies the foundations of professional ethics and speech culture. Having mastered these skills, students acquire research skills: oral and oral culture; communication with the audience; there are methods of time management. As a result, a connection is formed between thinking and enrichment of the student's worldview (Nazarov, 1970).

\section{Conclusion}

In conclusion, the relationship was revealed between formation of research competence through the research activities in bachelor students based on their analysis and generalization skills. In the process of higher education, bachelor's research activities were planned, and the formation of bachelor's research competencies using problem-based teaching methods was achieved. When acquiring professional competencies, bachelors must have the following research skills and abilities: the ability to set research goals and objectives; the ability to determine the sequence of research activities; selecting methods and tools that fit objectives of the research power; the ability to analyze, compare, substantiate one's position on the subject of research; the ability to highlight the main positions of the research; the ability to identify and substantiate the novelty of the study; the ability to assess the effectiveness of the results achieved; the ability to assess the theoretical and practical significance of the results obtained; the ability of students to plan educational and research activities; be able to design, organize and monitor 
research results.

\section{Conflicts of Interest}

The authors declare no conflicts of interest regarding the publication of this paper.

\section{References}

Akmatkulov, A. A. (1999). Professional Orientation of Mathematical Training of Future Specialists. Bulletin of KSNU, Series: Naturally Technical Sciences, 1, 15-20.

Ananin, P. V. (2015). Research Competence of Bachelors of Social Work: Stages of Formation. Bulletin of Vyatka State University, No. 10, 146-152.

Bekboev, I. B. (2003). Professional Competence Is the Basis of Quality Pedagogical Work (pp. 65-71). Soros Foundation Kyrgyzstan.

Borovikova, T. V. (2014). Formation of Research Competence in the Context of a TwoLevel Higher Education. Bulletin of the South Ural State Humanitarian Pedagogical University, 3, 17-23.

Galustyan, O., Borozdin, S., Pleshakov, M., Askhadullina, N., \& Radchenko, L. (2020). Formation of Research Competence of Students by Means of Mobile Education. International Journal of Interactive Mobile Technologies (IJIM), 14, 205-213. https://doi.org/10.3991/ijim.v14i14.15047

Guo, J., Chen, Z., \& Zheng, B. (2021). Postgraduate Competence and Academic Research Performance: The Mediating Role of Psychological Capital. Sustainability, 13, 6469. https://doi.org/10.3390/su13116469

Lekomtseva, E. N. (2009). Bachelor's Research Competencies. Yaroslavl Pedagogical Bulletin, 3, 92-96.

Letina, A. (2020). Development of Students' Learning to Learn Competence in Primary Science. Education Sciences, 10, 325. https://doi.org/10.3390/educsci10110325

Nazarov, M. N. (1970). Development of Logical Thinking of Students in the Process of Teaching Geometry in High School (32 p.). Dissertation.

Ostylovskaya, O. A., \& Shershneva, V. A. (2016). Formation of Bachelor's Research Competence in Teaching Mathematics in a Two-Level Training System. Bulletin of the Krasnoyarsk State Pedagogical University. V.P. Astaf'eva, 3, 85-90.

Pankratova, L. V. (2011). On the Formation of the Research Competence of Schoolchildren in the Context of Modern Mathematics Education. Bulletin of Vyatka State University, (4-3), 84-90.

Schultes, M. T., Aijaz, M., Klug, J., \& Fixsen, D. L. (2021). Competences for Implementation Science: What Trainees Need to Learn and Where They Learn It. Advances in Health Sciences Education, 26, 19-35. https://doi.org/10.1007/s10459-020-09969-8

Shapoval, S. A. (2019). Development of a Research Competence Model (ISC). Researcher, 3, 76-108.

Zikirova, G. (2020). Means of Research Activity in the Formation of Bachelor's Research Competence. Bulletin of Science and Practice, 6, 272-276. https://doi.org/10.33619/2414-2948/57/32

Zikirova, G. A. (2019). Business Attitude and Professional Competence. Science, New Technologies and Innovations of Kyrgyzstan, 1, 19-22.

Zikirova, G., Turdubaeva, K., Saadalov, T., \& Abdullaeva, Z. (2021). Teaching Mathemat- 
ics by Competency-Based Approach in Preparing Technical Students for Future Professional Working. Creative Education, 12, 1783-1791.

https://doi.org/10.4236/ce.2021.128135 